\title{
Dichloroacetate Enhances Myocardial Functional and Metabolic Recovery Following Global Ischemia
}

\author{
Joyce A. Wahr, MD, Keith F. Childs, and Steven F. Bolling, MD
}

This study was undertaken to determine the effect of dichloroacetate (DCA) on myocardial functional and metabolic recovery following global ischemia. Sixteen isolated rabbit hearts were subjected to 120 minutes of mildly hypothermic $\left(34^{\circ} \mathrm{C}\right)$ cardioplegic arrest with multi-dose, modified St. Thomas' cardioplegia. Following ischemia, hearts were reperfused with either a physiologic salt solution (PSS) as controls, (CON, $N=10$ ), or PSS containing DCA (DCA, $N=6$ ) at a concentration of $1 \mathrm{mmol} / \mathrm{L}$. Functional and metabolic indices were determined at baseline and at 15,30 , and 45 minutes of reperfusion. Results were analyzed using analysis of variance (ANOVA, Sheffe $F$ test) and significance was defined as $\boldsymbol{P}<\mathbf{0 . 0 5}$. Functional recovery was significantly better in hearts reperfused with DCA. Developed pressure (DP) recovered to $62 \pm 4 \%$ of baseline in DCA hearts. compared to $37 \pm 8 \%$ in CON hearts. Recovery of $\mathrm{dP} / \mathrm{dt}$ was also improved in DCA versus CON hearts $(67 \pm 5 v 43 \pm 10 \%)$. Coronary blood flow was not different between groups

G LOBAL MYOCARDIAL ischemia may result in poor functional recovery despite restoration of myocardial blood flow and repletion of substrate necessary for energy production. Hypothermic cardioplegic arrest is frequently used to provide myocardial protection during the period of mandatory myocardial ischemia that occurs during cardiac surgery. Even with these techniques, myocardial metabolic requirements are not eliminated, and functional and metabolic recovery is often impaired at reperfusion. Depletion of ATP levels and/or slow restoration of ATP levels following ischemia appear to be critical factors in this poor functional recovery, and agents that enhance repletion of ATP following ischemia should improve recovery. Oxidative phosphorylation is a critical source of cellular ATP; a key step in this metabolic pathway is the oxidation of pyruvate to acetyl CoA by the multi-enzyme complex pyruvate dehydrogenase (PDH). Dichloroacetate (DCA) has been shown to enhance the activity of PDH in virtually all tissues. ${ }^{1}$ and has been previously noted to limit the ST segment elevation associated with abrupt coronary occlusion in dogs.? DCA has also been shown to enhance glucose oxidation in isolated, endotoxin-shocked rat hearts. and to improve cardiac index in patients with severe lactic acidosis. ${ }^{4.5}$ DCA has been used in humans with little or no signs of toxicity. ${ }^{1.5}$ and thus has potential for use in paticnts with myocardial ischemia, especially the induced ischemia that occurs during cardiac surgery.

It was postulated that IDA, by increasing the activity of PDH, could enhance the functional and metabolic myocardial recovery following global ischemia during cold cardioplegic arrest in isolated, perfused rabbit hearts.

From the Deparments of Anesthesiology and Sisngen. Section of Thoracic Sungery, University of Michigan, Ann Arbor, MI.

Address for reprints requests to Joyce A. Wahr. MD, Department of Anesthesiology, University of Michigan. IG.323 0048. 1500 Medical Center Dr. Ann Artor, MI \$8109-(0)48.

Copyright 1994 by W.B. Saunders Company

$1053.0770 / 94 / 0802503.00 / 0$ either at baseline or during reperfusion, but myocardial oxygen consumption $\left(\mathrm{MVO}_{2}\right)$ was increased in the DCA versus CON hearts $(71 \pm 10 \%$ of baseline, $v 51 \pm 19 \%)$. Diastolic compliance during reperfusion was improved in those hearts receiving DCA, as was myocardial mechanical use efficiency (DP/ $/ \mathrm{MVO}_{2}$ ). Correction of myocardial tissue pH to baseline values was similar in both groups, indicating that the beneficial effect on functional recovery seen with DCA was not solely related to amelioration of acidosis. The enhanced myocardial function and improved metabolic status noted with DCA may result from increased oxidative phosphorylation due to altered pyruvate dehydrogenase (PDH) activity.

Copyright 1994 by W.B. Saunders Company

KEY WORDS: reperfusion, global myocardial ischemia, myocardial oxygen use

\section{MATERIAL AND METHODS}

Studies were performed in 16 isolated, perfused rabbit hearts. Male New Zealand rabbits weighing 3 to $4 \mathrm{~kg}$ were anesthetized with intravenously administered sodium pentobarbital $(10 \mathrm{mg} / \mathrm{kg})$, after which the heart was removed through a median sternotomy. The heart was rapidly excised and immersed in ice-cold physiologic salt solution (PSS) containing $118.0 \mathrm{mmol} / \mathrm{L} \mathrm{NaCl} .4 .0 \mathrm{mmol} / \mathrm{L}$ $\mathrm{KCI}, 22.3 \mathrm{mmol} / \mathrm{L} \mathrm{NaHCO} 3.11 .1 \mathrm{mmol} / \mathrm{L}$ glucose, $0.66 \mathrm{mmol} / \mathrm{L}$. $\mathrm{K}_{2} \mathrm{HPO}_{4}, 1.23 \mathrm{mmol} / \mathrm{L} \mathrm{MgCl}$, and $2.38 \mathrm{mmol} / \mathrm{L} \mathrm{CaCl} \mathrm{Cl}_{2}$ and was suspended from a perfusion column by aortic cannulation within 30) seconds of excision (Langendorff preparation). Coronary perfusion was established at $80 \mathrm{mmHg}$ with PSS equilibrated with $95 \%$ $\mathrm{O}_{2}-5 \% \mathrm{CO}_{2}$. The uxygen tension of the perfusate was maintained hetween 450 and $550 \mathrm{mmHg}$, and the perfusate temperature was kept at $37^{\circ} \mathrm{C}$ by means of a heat exchanger in the perfusion column (Fig 1).

After coronary perfusion was initiated, the heart generally regained sinus rhythm, but in the presence of persistent fibrillation, immediate direct-current cardioversion was carried out. While the heart was perfused on the column. a portion of the mitral valve with its chordac was excised, and a latex balloon, connected to tubing filled with saline solution, was introduced into the left ventricle through the mitral orifice (Fig 2 ). The balloon was sewn in place in such a way as to allow passive venting of the left ventricular (LV) cavity. The balloon was connected (o) a Statham P23Db (Gould. Akron. (IH) pressure transducer for continuous measurement of left ventricular pressure (LVP) and the first derivative of LVP (dP/dt), which were recorded on an IBM (Purchase. NY) analog to digital system. The superior vena cava and inferior vena cava were ligated. The pulmonary artery was cannulated to enable timed collection measurements of coronary flow and the cannula was connected to a Clark electrode (Chemical microsensor. Diamond Flectro-Tech, Inc. Ann Arbor. MI) for continuous measurement of the partial pressure of oxygen in the coronary effluent. Coronary flow was measured hy performing timed collections of the pulmonary effluent flow with a graduated cylinder. A Khuri Regional Tissue pH Monitor (Vascular Technology. (helmsford, MA) was placed in the mid-left ventricular myocardium for continuous recording of myccardial temperature and $\mathrm{pH}$.

Developed pressure (DP) was defined as peak systolic pressure (PSP) minus end-diastolic pressure (EDP). The product of heart rate: (HR) and DP (PRP. mmHgimin) was calculated to provide an 


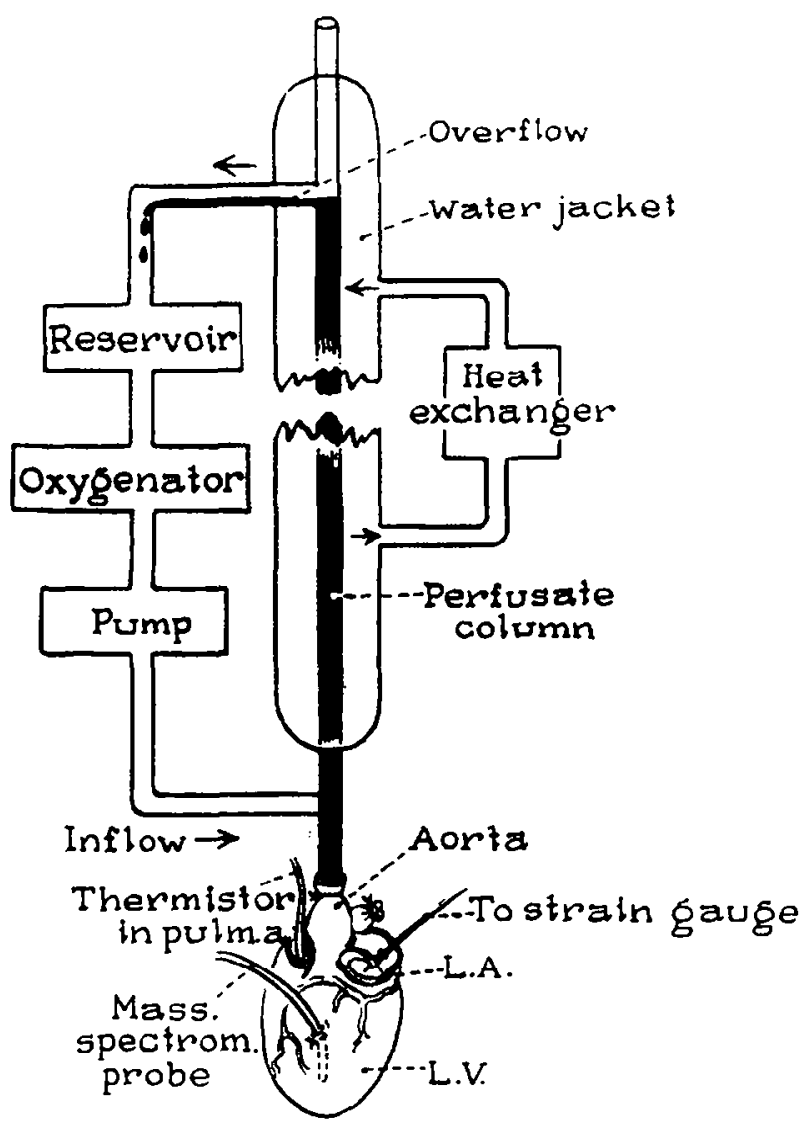

Fig 1. Perfusion column for isolated heart preparation. (Reprinted with permission.") estimate of changes in myocardial work. Myocardial oxygen consumption $\left(\mathrm{MVO}_{2}\right)$ was calculated as $\mathrm{MVO}_{2}=\mathrm{CF} \times\left[\left(\mathrm{PaO}_{2} \cdot \mathrm{PvO}_{2}\right)\right.$ $\times(\mathrm{c} / 760)]$, where $\mathrm{CF}$ is coronary flow $(\mathrm{mL} / \mathrm{min} / \mathrm{g}),\left(\mathrm{PaO}_{2}-\mathrm{PvO}_{2}\right)$ is the difference in the partial pressure of oxygen $\left(\mathrm{PO}_{2}, \mathrm{mmHg}\right)$ between perfusate and coronary effluent flow, and $\mathrm{c}$ is the Bunsen solubility coefficient of $\mathrm{O}_{2}$ in perfusate at $37^{\circ} \mathrm{C}\left(22.7 \mu \mathrm{L} \mathrm{O} \mathrm{O}_{2} /\right.$ at $\mathrm{m} / \mathrm{mL}$ perfusate)

After completing instrumentation and performing calibrations, left ventricular ballonn volumes were varied over a range of values to construct modified left ventricular function curves. In this manner. it was possible to define a specific balloon volume (end-diastolic volume. [EDV]) that was associated with a developed pressure between 100 and $140 \mathrm{mmHg}$. This volume was maintained the same for each heart during baseline and reperfusion conditions. The intraventricular balloon volumes were not adjusted to produce specific end-diastolic pressures (rather, a defined level of systolic pressure development), but end-diastolic pressures at baseline greater than $10 \mathrm{mmHg}$ were not considered acceptable. Hearts characterized by developed pressures less than 10) $\mathrm{mmHg}$ or greater than $140 \mathrm{mmHg}$ were not used. After determination of the best EDV for each heart, the balloon volume was increased in increments, permitting estimation of diastolic stiffness at baseline and reperfusion by measuring the slope of linearized EDP versus EDV curves for each heart.

After a 30-minute stabilization period, baseline measurements were made in each heart. Hearts were then rendered globally ischemic by interruption of the perfusion column immediately above the aortic cannulation site. The intraventricular balloon was deflated, and $15 \mathrm{~mL}$ of cardioplegia (modified St. Thomas's solution. $4^{\circ} \mathrm{C}$ ) were administered. All hearts were maintained at $34^{\circ} \mathrm{C}$ by means of a circulating water jacket during 120 minutes of total ischemia. All hearts received $10 \mathrm{~mL}$ of cardioplegic solution every 30 minutes during ischemia. Multidose administration of

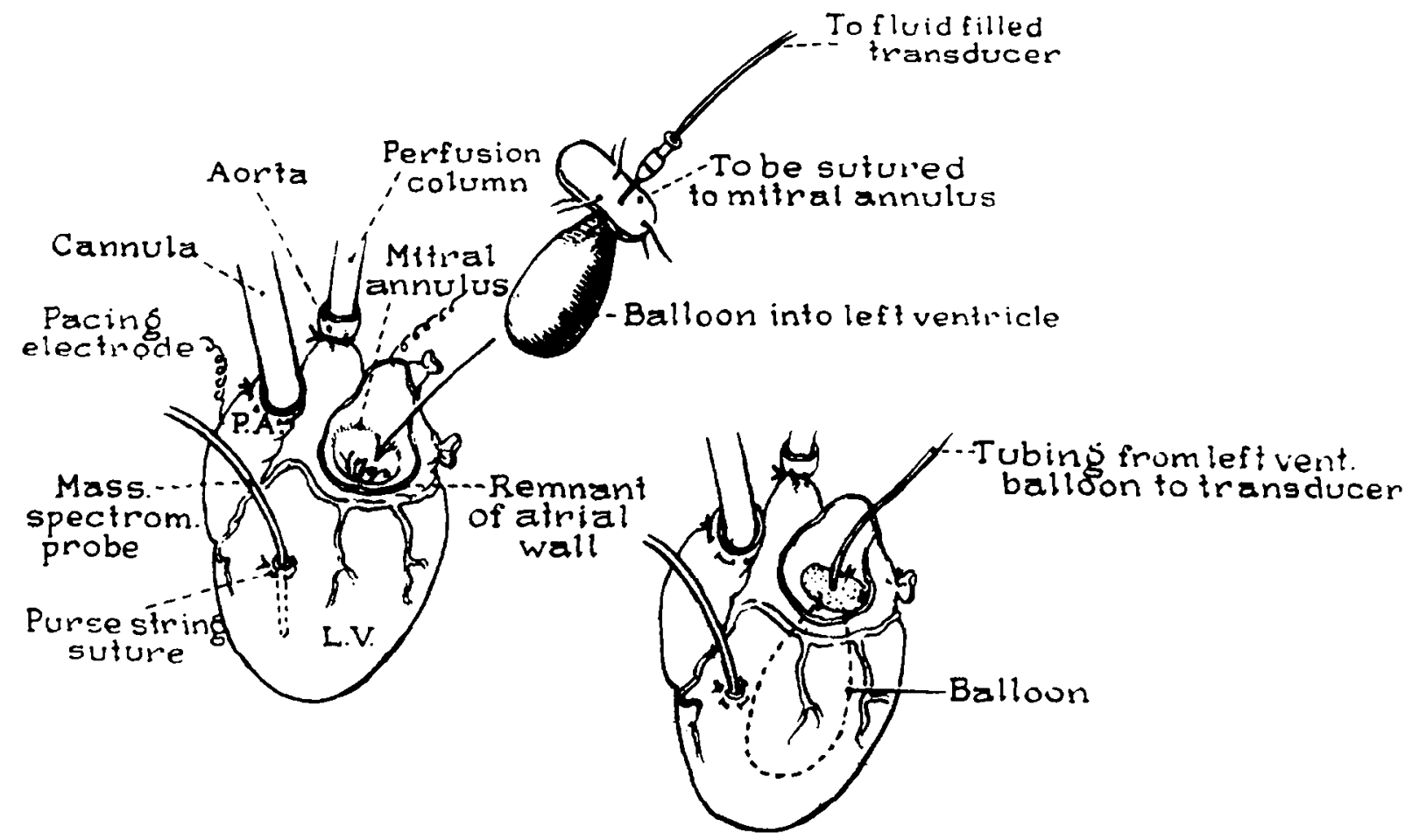

Fig 2. Balloon inserted into left vontricular cavity for recording functional measurements. Abbreviations: LV, left ventricle; PA, pulmonary artery. (Reprinted with permission.") 
cardioplegic solution is used commonly in the clinical arena and is consistent with the experimental studies reported previously

When the 2-hour ischemic period was ended. the hearts were reperfused at $80 \mathrm{mmHg}$ with oxygenated PSS at $37^{\circ} \mathrm{C}$ and the water bath temperature was increased to $37^{\circ} \mathrm{C}$. Control hearts $(\mathrm{N}=10)$ were reperfused with the same PSS used during haseline, and DC A hearts $(\mathrm{N}=6)$ were reperfused with PSS containing $1 \mathrm{mM} \mathrm{DCA} A$ fresh solution of DCA (Sigma (hemicals, St. Louis, MO) was prepared for each experiment, and the solution was adjusted to a pH of 7.35 to 7.45. Defibrillation was performed as needed during the initial 3 minutes of reperfusion. During the first 15 minutes of reperfusion the intraventricular balloon was kept deflated to simulate the beating, nonworking condition. After the initial 15 minutes of reperfusion, the L.V balloon was retilled to the preischemic EDV and hemodynamic and metabolic measurements were made. The balloon remained inflated for the remainder of the reperfusion period and measurements were obtained after 15.30, and 45 minutes of reperfusion. Diastolic stiffness (compliance) was determined as at baseline.

After 45 minutes of reperfusion, all hearts were removed from the perfusion apparatus. Wet weight of the heart was determined at the conclusion of each experiment after trimming the great vessels and fat and blot drying. The myocardial water content was determined by weighing a fresh specimen of myocardium. allowing this sample to desiccate for 48 hours at $80^{\circ} \mathrm{C}$. and then reweighing the sample. Percent water was calculated using the formula $\left([1-\right.$ dry weight $i$ wet weight $\left.] \times 100=0 ; \mathrm{H}_{2} \mathrm{O}\right)$.

This protocol was approved by the University of Michigan Institutional Animal Care and Use Committec and complied with the "Principles of Laboratory Animal Care" and the "Guide for the Care and Use of Laboratory Animals" (NIH Publication No. 80.23. revised 1978).

Values reported in the lext, tables. and figures are means \pm standard deviation. Data were evaluated with repeated measures analysis of variance (ANOVA). When significant $F$ values were obtained, Scheffe's test was used to distinguish which time periods or groups differed from one another significantly. Differences were considered significant when $P<0.05$.

\section{RESULTS}

There were no significant differences at baseline for heart rates, $\mathrm{DP}$, or $\mathrm{dP} / \mathrm{dt}$ values between control hearts and DCA hearts, and baseline DP averaged $110 \mathrm{mmHg}$ for all hearts. Left ventricular systolic and diastolic functional measurements of DP and $\mathrm{dP} / \mathrm{dt}$ made after 45 minutes of reperfusion are shown in Table 1 as percent recovery of function compared to baseline values. Diastolic stiffness (or compliance, $\triangle E D P / \triangle E D V)$ is expressed as the slope of the line that best described the change in end-diastolic pressure for each $0.1 \mathrm{~mL}$ change in end-diastolic volume.

After 120 minutes of hypothermic ischemia and 45

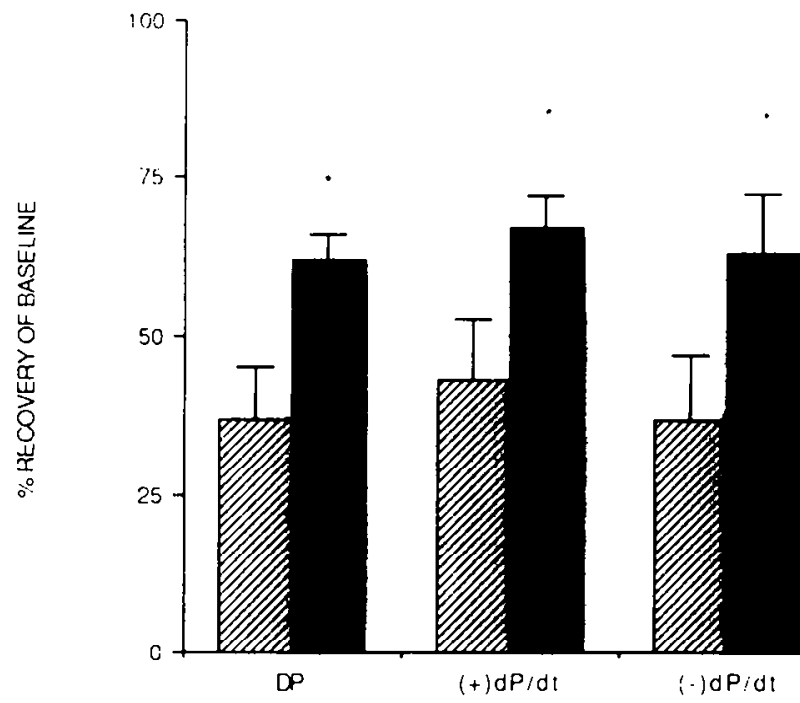

Fig 3. Functional recovery at $\mathbf{4 5}$ minutes of reperfusion. Values are means \pm standard deviation. $P<0.05$. . CON; $\square$, DCA.

minutes of reperfusion, control hearts recovered $37 \pm 8 \%$ of baseline DP and $43 \pm 10 \%$ of baseline $\mathrm{dP} / \mathrm{dt}$ (Fig 3 ). Hearts reperfused with DCA showed significantly better recovery of function, to $62 \pm 4 \%$ of baseline DP and $67 \pm$ $5 \%$ of baseline dP/dt $(P<0.05$ versus control hearts $)$.

Diastolic stiffness was significantly improved in hearts reperfused with DCA compared to CON (Fig 4). After 45 minutes of reperfusion, the control hearts were characterized by a higher diastolic stiffness slope value of 156.7 (a $15.6 \pm 0.8 \mathrm{mmHg}$ rise in EDP for each $0.1 \mathrm{~mL}$ increase in EDV) versus a diastolic stiffness value of $82.6 \pm 11$ in those hearts reperfused with DCA $(P<0.05)$.

Myocardial metabolic indices are shown in Table 2. Coronary blood flow was not different between control hearts and those reperfused with DCA at baseline or at any time during reperfusion. Baseline values were $41 \pm 9$ $\mathrm{mL} / \mathrm{min}$ and $38 \pm 5 \mathrm{~mL} / \mathrm{min}$ in the CON and DCA hearts. respectively, and $38 \pm 12$ and $29 \pm 7$ at 45 minutes of reperfusion. Myocardial oxygen consumption was not differcnt between groups at baseline but was increased in DCA reperfused hearts versus control hearts at 45 minutes of reperfusion (Fig 5). Bascline $\mathrm{MVO}_{2}$ was $63 \pm 10 \mathrm{~mL} / \mathrm{g} / \mathrm{min}$ and $67 \pm 10 \mathrm{~mL} / \mathrm{g} / \mathrm{min}$ in control and DCA hearts. respectively, and at 45 minutes of reperfusion was $32+11$ in control versus $48 \pm 12$ in DCA hearts $(P<0.05)$. Likewise. $\% \mathrm{O}_{2}$ extraction was not different between groups

Table 1. Myocardial Functional Indices: Baseline and 45' Reperfusion

\begin{tabular}{|c|c|c|c|c|c|c|c|}
\hline Group & $N$ & $\begin{array}{c}\text { Developed } \\
\text { Pressure } \\
\text { (mmHgl }\end{array}$ & $\begin{array}{c}\% \text { Recovery } \\
\text { DP }\end{array}$ & $\begin{array}{c}\mathrm{d} P / \mathrm{dt} \\
(\mathrm{mmHg} / \mathrm{sec})\end{array}$ & $\begin{array}{c}\% \text { Recovery } \\
\mathrm{dP} / \mathrm{dt}\end{array}$ & $\begin{array}{c}(-) \mathrm{dP} / \mathrm{dt} \\
(\mathrm{mmHg} / \mathrm{sec})\end{array}$ & $\begin{array}{c}\% \text { Recovery } \\
1-\mathrm{IdP} / \mathrm{dt}\end{array}$ \\
\hline Control & 10 & & & & & & \\
\hline Baseline & & $103 \div 13$ & & $1.550 \pm 247$ & & $1,282 \pm 200$ & \\
\hline $45^{\prime}$ Reperf & & $39 \pm 12$ & $37 \div 8$ & $670 \pm 190$ & $43 \div 10$ & $483 \pm 146$ & $38 \pm 10$ \\
\hline DCA & 6 & & & & & & \\
\hline Baseline & & $118 \pm 14$ & & $1,758 \pm 271$ & & $1.290 \pm 131$ & \\
\hline 45' Repert & & $73 \pm 11^{*}$ & $62 \pm 4^{*}$ & $1,175 \pm 174^{*}$ & $67 \pm 5^{*}$ & $810 \pm 120^{*}$ & $63 \pm 10^{*}$ \\
\hline
\end{tabular}

- $P$ < 0.05 
Fig 4. Diastolic compliance ot beseline and at 45 minutes of reperfusion. $y$ axis is the linearized slope of EDP / EDV. Values are means \pm standard deviation. $\bullet P<0.05$. F, CON; D, DCA.

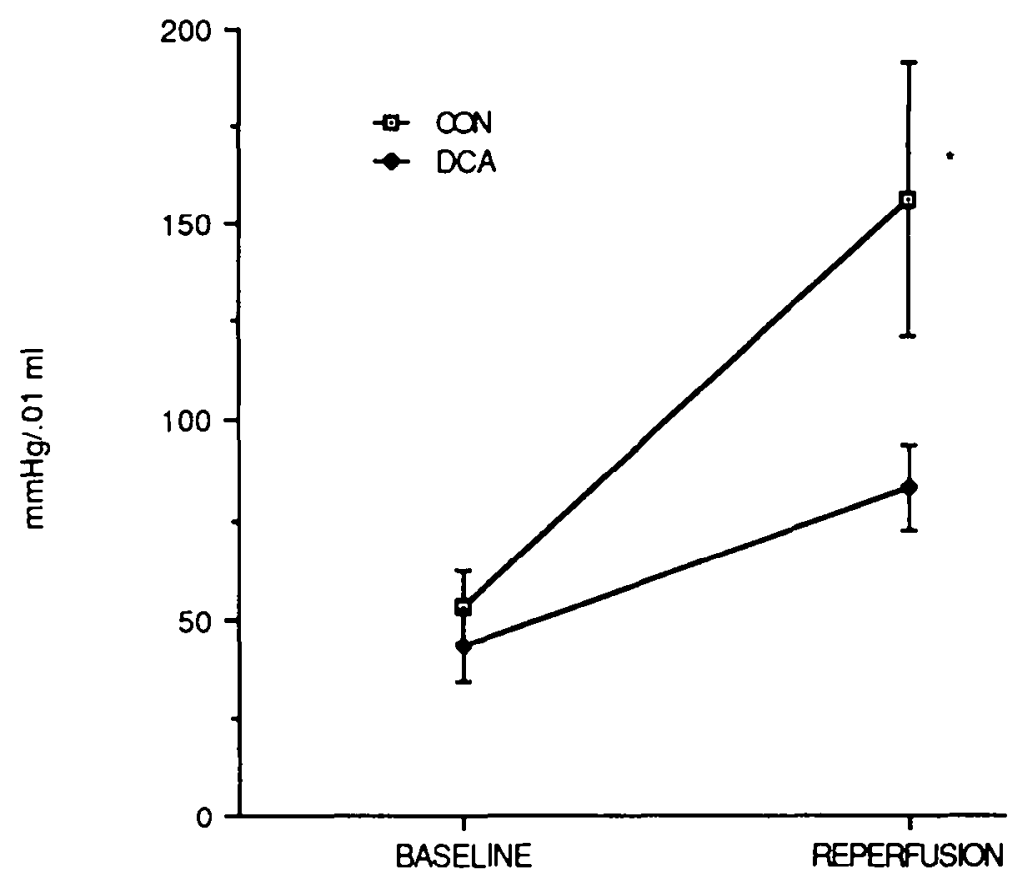

at baseline, but was increased in DCA hearts versus control hearts at 45 minutes of reperfusion $(74 \% \pm 6 \% v$ $40 \% \pm 17 \%, P<0.05)$.

The change in intramyocardial $\mathrm{pH}$ during rcperfusion was not different between control hearts and those receiving DCA as measured by this technique (Fig 6).

\section{DISCUSSION}

These results indicate that DCA administration during reperfusion significantly improves myocardial functional and metabolic recovery following cold, cardioplegic global ischemia. The mechanism of this enhanced recovery may be duc either to metabolic alterations or inotropic support of the reperfused myocardium.

Myocardial ischemia and the effect of reperfusion have been extensively studied, often using isolated heart preparations. Thesc preparations are uscful in that metabolic processes can be manipulated in a wide variety of ways and the effect of such manipulation on functional recovery studied. There are several types of global ischemic models in the literature: (1) warm, working global ischemia with neither substrate nor oxygen supplied, (2) warm working global anoxia with substrate perfusion, (3) cold cardioplegic arrest with neither substrate nor oxygen supplied. The first two represent the conditions of sudden death or cardiac

arrest (myocyte necrosis), whereas the latter mimics the conditions of the heart during bypass or the heart harvested for transplantation (myocyte stunning). The ability of the myocardial cell to recover functionally following an ischcmic insult is variable, depending on the duration of the ischemia and the metabolic conditions existing prior to, during, and after ischemia. Although the final pathway for recovery appears to be repletion of high-energy phosphate or ATP levels, it is not yet certain which conditions before or after ischemia enable the cell to restore energy levels to normal during reperfusion. Factors that appear to diminish the cell's ability to regenerate ATP include decreased availability of adenosine nucleotides, ${ }^{n-9} \mathrm{Ca}^{++}$levels, ${ }^{10.11}$ and the accumulation of glycolytic metabolites, including lactate, $\mathrm{H}^{+}$. NADH, and oxygen free radicals. ${ }^{11-13}$

Under normal metabolic conditions. the metabolism of free fatty acids provides nearly $70 \%$ of the high-energy phosphate bonds required for normal function. ${ }^{14}$ Following a period of hypoperfusion or total global ischemia, the myocardial cell is critically dependent on glycolysis for functional recovery during reperfusion. ${ }^{14,15}$ During ischemia, as the supply of cellular oxygen diminishes, electron flux through the electron transport chain falters and as NADH accumulates, oxidative phosphorylation ceases. The consequent decrease in ATP levels directly stimulates

Table 2. Myocardial Metabolic Indices: Baseline and 45 Reperfusion

\begin{tabular}{|c|c|c|c|c|c|c|c|}
\hline Group & $\mathbf{N}$ & $\underset{(\mathrm{mL} / \mathrm{g})}{\mathrm{CBF}}$ & $\begin{array}{c}\% \text { Recovery } \\
\text { CBF }\end{array}$ & $\begin{array}{c}M V O \\
\mathrm{mLig} / \mathrm{min}\end{array}$ & $\begin{array}{c}\% \text { Recovery } \\
\mathrm{MVO}_{2}\end{array}$ & $\mathrm{DP} / \mathrm{MVO}_{2}$ & $\begin{array}{l}\text { \% Recovery } \\
\text { DP/MVO }\end{array}$ \\
\hline Control & 10 & & & & & & \\
\hline Baseline & & $41 \pm 9$ & & $63 \pm 10$ & & $1.7 \pm 0.4$ & \\
\hline 45' Reperf & & $38 \pm 12$ & $92 \pm 23$ & $32+11$ & $51 \pm 19$ & $1.3 \pm 0.5$ & 76 \\
\hline DCA & 6 & & & & & & \\
\hline Baseline & & $38 \pm 5$ & & $67 \pm 10$ & & $1.8 \pm .4$ & \\
\hline 45' Reperf & & $29 \pm 7$ & $75 \pm 5$ & $48 \pm 12^{*}$ & $72 \pm 10^{*}$ & $1.6 \pm 0.4$ & 88 \\
\hline
\end{tabular}

$-P<0.05$ 


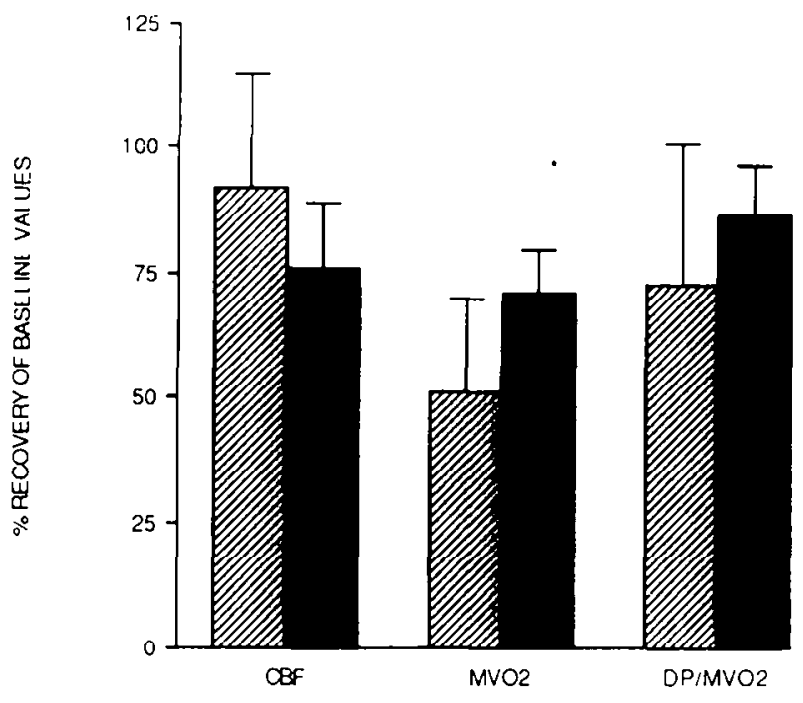

Fig 5. Myocardial metabolic recovery at $\mathbf{4 5}$ minutes of reperfusion. Abbreviations: CBF, coronary blood flow; $\mathrm{MVO}_{2}$, myocardial oxygen consumption; $\mathrm{DP} / \mathrm{MVO}_{2}$, developed pressure per myocardial oxygen consumption. Values are means \pm standard deviation. $* P<0.05$.

anaerobic glycolysis, increasing pyruvate production; the $\mathrm{NAD}^{+}$required for this pathway comes from the formation of lactate from pyruvate. In addition, the accumulation of reduced $\mathrm{NADH}$ inhibits the activity of pyruvate dehydrogenase (PDH), the multienzyme complex responsible for oxidation of pyruvate to acetyl $\mathrm{CoA}$ and thereby its entry into the Krebs cycle. ${ }^{1,16}$ Cellular ischemia thus quickly results in depletion of ATP stores and accumulation of lactatc and $\mathrm{H}^{+}$ions.

The mechanisms of the beneficial effect of DCA that have been found may relate to DCA's ability to stimulate the activity of pyruvate dehydrogenase. ${ }^{1,3.12 .16}$ DCA has been shown to increase the activity of PDH in brain, heart. skeletal muscle, adipose tissue, platelet-enriched plasma and fibroblasts with maximal stimulation generally occurring at a concentration of $1 \mathrm{mmol} / \mathrm{L}$.: By directly increasing the activity of PDH. DCA mav override the negative feedback loop of NADH accumulation. increasing the amount of pyruvate metabolized to acetyl CoA, thus increasing oxidative phosphorylation during reperfusion.

DCA's effect on metabolic and mechanical recovery following global ischemia has been studied in various isolated heart modcls. In a model of warm, working, global ischemia, Racey-Burns et all: showed that rat hearts reperfused with DCA had lower lactate levels, improved myocardial function, and elevated ATP levels compared to control hearts. In another model of warm, working ischemia in rat hearts. McVeigh and Lopashuck is first inhibited glycolysis by infusion of free fatty acids (FFA), then subjected the hearts to 25 to 30 minutes of warm ischemia. Reperfusion was accomplished with a PSS containing FFA or PSS + FFA + DCA. Functional recovery and glucose oxidation were enhanced with DCA, but ATP levels were not different from control hearts. Finally, Mallet et al ${ }^{15}$ studied guinca pig hearts subjected to 25 minutes of global low-flow perfusion with concurrent norepinephrine infusion to exhaust glycogen stores. The hearts were reperfused with a variety of solutions, including glucose alone, glucose and pyruvate. glucese and DCA. and pyruvate and DCA. They found that DCA and glucose, when added to the PSS used during reperfusion, increased functional recovery. increased ATP levels, and lowered lactate levels. There are no previous reports of DC.A use in a model of cold. cardioplegic arrest. However, these results indicate that the beneficial effect of DCA is not temperature-dependent.

Although DC.A is known to limit lactic acidosis in hypoxic settings..$^{1.5}$ and decreased lactate levels in two isolated heart reperfusion models, ${ }^{2} .1 \mathrm{~h}$ no difference was found between groups in recovery to bascline tissue $\mathrm{pH}$. Myocar-

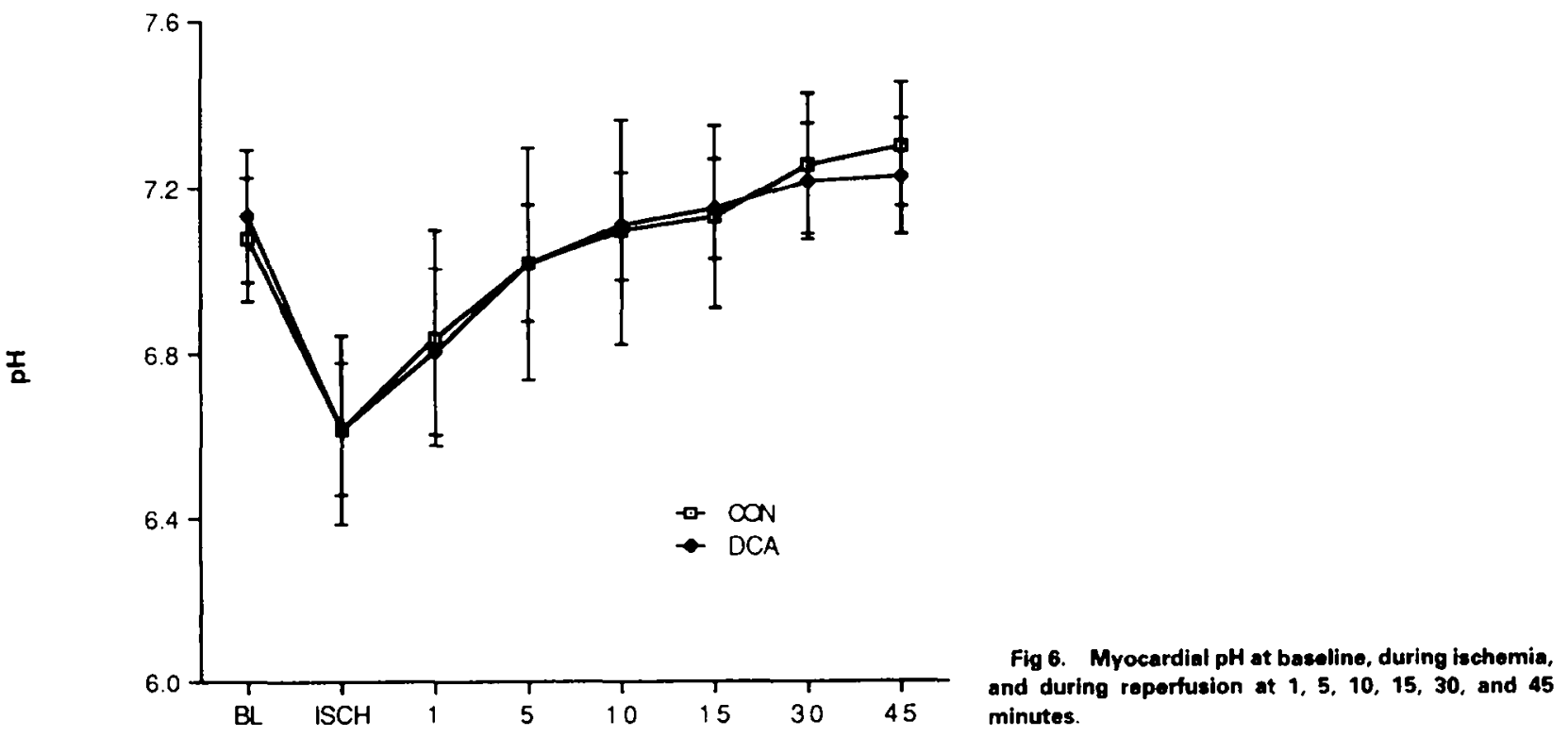


dial $\mathrm{pH}$ returned to 7.2 within 2 minutes of reperfusion in both control and DCA hearts, most likely due to rapid washout of anaerobic byproducts with a $\mathrm{pH}$-balanced reperfusion solution. Therefore, the improved functional recovery seen with DCA in this model cannot be simply ascribed to amelioration of acidosis.

DCA may also have inotropic propertics. When studied in a model of endotoxin-shocked rat hearts without ischemia, DCA enhanced the inotropic effect of both amrinone and ouabain and independently increased glucose oxidation in these hearts. ${ }^{3}$ The enhanced oxygen consumption noted with DCA administration could be either cause or effect of improved function. An increase in myocardial mechanical use efficiency was found, ie, the amount of work done per milliliter of oxygen consumed, in hearts reper- fused with DC.A. This interesting effect has been noted in other studics of DCA, including one performed in 9 patients with known coronary artery disease, ${ }^{17}$ and in a study of hypoxic lactic acidosis in dogs. ${ }^{18}$ An improvement in both myocardial function and oxygen use during DCA administration were noted, but can only be speculated whether the myocardial functional recovery it noted was due to a direct inotropic effect of DCA, due to enhanced oxidative phosphorylation and ATP repletion during reperfusion, or resulted from an altered myocardial oxygen use.

In summary, DCA is a promising new agent capable of enhancing myocardial functional recovery and improving mechanical use efficiency when administered following induced global ischemia, but further study will be required to delineate the exact nature of its beneficial effect.

\section{REFERENCES}

1. Stacpoole PW: The pharmacology of dichloroacetate. Metabolism 38:1124-1144. 1989

2. Mjos OD, Miller NE, Riemersma RA, Oliver MF: Effects of dichloroacetate on myocardial substrate extraction, epicardial ST-segment elevation, and ventricular blood fow following coronary occlusion in dogs. Cardiov Res 10:427-436, 1976

3. Burns AH, Summer WR, Burns LAR, Shepherd RE: Inotropic interactions of dichloroacetate with amrinone and ouabain in isolated hearts from endotoxin-shocked rats. J Cardiov Pharmacol 2:379-386, 1988

4. Stacpoole PW. Harman EM. Curry SH, et al: Treatment of lactic acidosis with dichloroacetate. N Engl J Med 309:390)-396, 1983

5. Stacpoole PW, Lorenz AC, Thomas RG, Harman EM Dichloroacetate in the treatment of lactic acidosis. Ann Int Med 108:58-63, 1988

6. Foker JE, Einzig S. Wang T: Adenosine metabolism and myocardial preservation. J Thorac Cardiovasc Surg 80:506-516, 1980)

7. Reibel DK. Rovetto MJ: Myocardial adenosine salvage rates and restoration of ATP content following ischemia. Am J Physiol 237:H247-H252, 1979

8. Bolling SF. Bies LE, Gallagher KP, Bove EL: Enhanced myocardial protection with adenosine. Ann Thorac Surg 47:809. 815,1989

9. Bolling SF, Bove EL, Gallagher KP: ATP precursor depletion and postischemic myocardial recovery. J Surg Res 50:629-633, 1991
10. Naylor WG: The role of calcium in the ischemic myocardium. Am J Pathol 102:262-270, 1981

11. Neely JR. Grotyohann LW: Role of glycolytic products in damage to ischemic myocardium: Dissociation of adenosine triphos. phate levels and recovery of function of reperfused ischemic hearts. Circ Res 55:816-824, 1984

12. Raccy-Burns LA, Burns AH, Summer WR, Shepherd RE: The effect of dichloroacetate on the isolated no flow arrested rat heart. Life Sciences 44:2015-2023, 1989

13. Myers ML. Bolli R, Lekich RF, et al: Enhancement of recovery of myocardial function by oxygen free-radical scavengers after reversible regional ischemia. Circulation 72:915-921, 1985

14. McVeigh JJ, Lopaschuk GD: Dichloruacetate stimulation of glucose oxidation improves recovery of ischemic rat hearts. Am J Physiol 28:H1079-1085, 1990)

15. Mallet RT, Hartman DA, Bunger R: Glucose requirement for postischemic recovery of perfused working heart. Eur J Biochem 188:481-493, 1990

16. Whitehouse S, Cooper RH, Randle PJ: Mechanism of activation of pyruvate dehydrogenase by dichloroacetate and other halogenated carboxylic acids. Biochem J 142:761-774. 1974

17. Wargovich TJ, MacDonald RG, Hill JA, et al: Myocardial metabolic and hemodynamic effects of dichloroacetate in coronary artery disease. Am J Cardiol 61:65-70, 1988

18. Wahr JA, Ullrich K, Bolling SF: The use of dichloroacetate in the treatment of overwhelming hypoxic acidosis. J Cardiothorac Anesth 199.3 8:64-69.1994 